\title{
Desafios da Gestão na Saúde: Possíveis Contribuições da Psicologia Organizacional e do Trabalho
}

\author{
Gina Lorena de Carvalho Barboza Moreira; Susanne Pinheiro Costa e Silva
}

\begin{abstract}
Resumo: O estudo objetivou desvelar possibilidades de contribuições da Psicologia Organizacional e do Trabalho (POT) para a gestão do Sistema Único de Saúde (SUS). Foi realizada revisão da literatura através de 15 artigos publicados nas bases de dados Scielo e Biblioteca Virtual em Saúde (BVS) na língua portuguesa principalmente nos últimos 07 (sete) anos referentes à POT e as principais dificuldades enfrentadas por Gestores da Saúde. Dos quais 09(nove) foram utilizados. Os resultados obtidos revelaram que a atuação do psicólogo é de grande importância, pois o Psicólogo Organizacional possui habilidades técnicas que, somadas ao conhecimento da equipe administrativa, tende a uma administração mais eficaz. Com a ajuda dele, a organização poderá oferecer aos seus colaboradores um ambiente melhor e soluções aos problemas organizacionais, fazendo com que os funcionários possam sentir-se mais motivados para desempenhar bem suas tarefas, além de dar assistência nos recrutamentos, na gestão e no desenvolvimento dos Recursos Humanos no cumprimento da missão, objetivos e no progresso das organizações.
\end{abstract}

Palavras-chave: Psicólogo Organizacional, Gestão da Saúde, Administração do SUS

\section{Management Challenges in Health: Possible Contributions of Organizational and Work Psychology}

\begin{abstract}
The study aimed to unveil possibilities of contributions of Organizational and Work Psychology (OWP) for the management of the Sistema Único de saúde (SUS). A literature review was conducted through 15 articles published by scielo and Biblioteca Virtual em Saúde (BVS) in Portuguese mainly in the last seven (07) years regarding OWP the and the main difficulties faced by the health managers. Of which 09 (nine ) were used The results showed that the psychologist is of great importance, because the organizational psychologist has technical skills, added to the knowledge of the management team tends to a more effective administration. With his help, the organization can offer its employees a better environment and solutions to organizational problems, so that employees can feel more motivated to perform well their duties, and assist in the recruitment, management and development Human Resources in fulfilling the mission, objectives and progress of organizations.
\end{abstract}

Keywords: Organizational Psychologist, Health Management, Administration SUS.

\section{Introdução}

Pesquisas recentes apontam a saúde como principal preocupação das pessoas, ficando atrás, em algumas situações ou países, apenas de questões econômicas de sobrevivência, como desemprego e renda insuficiente.

\footnotetext{
${ }^{1}$ Graduada em Psicologia pela Universidade Federal do Vale do São Francisco (2013). Pós-graduanda em Gestão em Saúde pela referida universidade. Com atuação profissional em dependência química e assistência social. E-mail: ginnalorenna@hotmail.com;

${ }^{2}$ Doutora pelo Programa de Pós Graduação em Psicologia da Universidade Federal do Espírito Santo - UFES. Mestrado em Enfermagem Atenção à Saúde pela Universidade Federal do Rio Grande do Norte (UFRN) e graduação em Enfermagem pela Universidade Estadual da Paraíba (UEPB). Docente efetiva do Mestrado em Psicologia UNIVASF - disciplina Metodologia da Pesquisa em Psicologia. Docente da Especialização Gestão em Saúde UNIVASF. Docente das Residências em Saúde da Família, Mental e Intensivismo. Professora Adjunto III do Colegiado de Enfermagem da Universidade Federal do Vale do São Francisco - UNIVASF. E-mail: susanne.costa@univasf.edu.br.
} 
Esta relevância faz com que a política, ações e serviços de saúde assumam cada vez mais importância na agenda das sociedades modernas. Das instituições contemporâneas, o hospital é percebido como um dos mais impermeáveis à mudança, devido ao baixo grau de interação entre as profissões e departamentos, fragmentação da prática clínica, grande subordinação dos usuários aos serviços e pouco governo dos gestores para atuar sobre as corporações (LORENZETTI, 2014).

Cabe destacar que, a cultura organizacional dos Hospitais, de modo geral apresenta uma série de dificuldades, sendo que as mais significativas ocorrem nas dimensões de relacionamento interpessoal, fluxo de informações/comunicação, nível de estresse e desejos de mudanças. Um dos aspectos que mais tem chamado à atenção, quando se trata da avaliação dos serviços, é o despreparo dos profissionais e demais trabalhadores para lidar com a dimensão subjetiva que toda prática de saúde necessita. Atrelado a esse aspecto, outro que se destaca é a presença de modelos de gestão centralizados e verticais, desapropriando o trabalhador de seu processo de trabalho (ROSA; ISABEL, 2007).

É sabido que a atuação do psicólogo é de grande importância, pois com a ajuda dele a organização poderá oferecer aos seus colaboradores um ambiente melhor e soluções aos problemas organizacionais, fazendo com que os funcionários possam sentir-se mais motivados para desempenhar bem suas tarefas.

Ninguém melhor que o Psicólogo Organizacional para dirigir e realizar a tarefa de Gestão de Pessoas, uma vez que o objetivo desta área da organização compreende todos os conceitos elementares que o especialista na conduta humana, orientado para o comportamento organizacional, conhece e domina. Além disso, conhece os princípios do comportamento individual e grupal, os fundamentos da aprendizagem de comportamentos, o seu reforço, a motivação e satisfação laboral, assim como a organização e direção eficaz de equipes de trabalho (CHAVES, 2010).

Para Zanelli (1994,) o objetivo do psicólogo na organização é identificar e analisar as necessidades derivadas das atividades de trabalho, suas condições e implicações. Fiorelli (2007) destaca que a psicologia na organização preocupa-se com o efeito que os diferentes fenômenos provocam sobre a atividade psicológica, por exemplo, a maneira como o individuo se comporta diante de uma situação de estresse. 
Nesses termos, podemos verificar que a psicologia contribui e trás muitos benefícios à organização. Ela precisa de espaço para colocar suas atividades em prática e ajudar a mesma a manter o foco em um ambiente saudável e prazeroso de se trabalhar (ROSECLEIA, 2011).

Destarte, esse estudo tem como objetivo desvelar as possibilidades de contribuições da Psicologia Organizacional e do Trabalho (POT) para a Administração no Setor da Saúde. Compreender de que modo à psicologia Organizacional - que trata dos fenômenos psicológicos provenientes do ambiente das organizações - pode colaborar com as questões pertinentes à Gestão na Saúde, beneficiará não somente os psicólogos, que se interessam por esta área, mais também aos Gestores. Afinal, torna-se contraditório pensar em promoção de saúde onde o ambiente organizacional está em processo de adoecimento.

Nesse sentido, fortalecer-se-á a relação entre Gestão hospitalar e psicologia, pois, embora seja perceptível a demanda emocional que permeia os espaços de saúde, pouco têm se voltado o olhar para as contribuições que esta ciência pode lançar mão. Além disso, a produção teórica acerca desse assunto há de despertar o interesse dos profissionais que atuam na área de Gestão a fazerem uso desse saber teórico-prático, atentando sobre a necessidade e importância de humanizar cada vez mais os espaços de trabalho.

\section{Método}

Para realizar esta revisão bibliográfica da Psicologia Organizacional, foi feita uma revisão literária de artigos acadêmicos produzidos nos últimos 07 (sete) anos acerca dessa temática, que me permitiu vislumbrar as suas possibilidades na Gestão hospitalar.

Para que o estudo fosse realizado, realizou-se busca nas bases de dados Scielo e Biblioteca Virtual de Saúde (BVS), através dos seguintes descritores e suas combinações na língua portuguesa: "Psicologia Organizacional", "Gestão da saúde", "desafios do SUS". Excluíram-se aqueles que não tratassem da atuação do Psicólogo Organizacional, bem como os que não falavam sobre as principais dificuldades encontradas pelos Gestores da Saúde, 06(seis no total). Os critérios de inclusão definidos para a seleção dos artigos foram: artigos publicados em português; artigos na íntegra que retratassem a temática referente à revisão 
Id on Line Revista Multidisciplinar e de Psicologia

Id on Line Multidisciplinary Journal and Psycology

integrativa e aqueles publicados e indexados nos referidos bancos de dados principalmente nos últimos sete anos. Resultaram dessa seleção oito artigos, descritos no Quadro 1.

Quadro 1. Artigos levantados nas bases de dados Scielo e Google acadêmico sobre Psicologia Organizacional e Gestão da saúde.

\begin{tabular}{|c|c|c|c|c|}
\hline Procedência & $\begin{array}{l}\text { Título do } \\
\text { artigo }\end{array}$ & Autores & Periódico & $\begin{array}{c}\text { Considerações/ } \\
\text { Temática }\end{array}$ \\
\hline BVS & $\begin{array}{l}\text { O Sistema de } \\
\text { Saúde } \\
\text { Brasileiro: } \\
\text { história, } \\
\text { avanços e } \\
\text { desafios }\end{array}$ & $\begin{array}{c}\text { Paim J, } \\
\text { Travassos C, } \\
\text { Almeida C, } \\
\text { Bahia L, } \\
\text { Macinko J }\end{array}$ & $\begin{array}{c}\text { Séries } \\
\text { Saúde no } \\
\text { Brasil, maio } \\
\text { de } 2011\end{array}$ & $\begin{array}{c}\text { Examina a } \\
\text { organização, o } \\
\text { desenvolvimento } \\
\text { histórico e o estado } \\
\text { atual do sistema de } \\
\text { saúde brasileiro. }\end{array}$ \\
\hline Scielo & $\begin{array}{l}\text { Gestão em } \\
\text { Saúde no } \\
\text { Brasil: Diálogo } \\
\text { com gestores } \\
\text { públicos e } \\
\text { privados }\end{array}$ & $\begin{array}{c}\text { Lorenzetti J, } \\
\text { Lanzoni } \\
\text { GMM, } \\
\text { Assuiti LFC, } \\
\text { Pires DEP, } \\
\text { Ramos FRS }\end{array}$ & $\begin{array}{l}\text { Texto } \\
\text { contexto } \\
\text { Enferm., } \\
\text { Abr-Jun de } \\
\quad 2014\end{array}$ & $\begin{array}{l}\text { Estudo com objetivo } \\
\text { de identificar os } \\
\text { principais problemas } \\
\text { da gestão em saúde } \\
\text { no Brasil, a partir da } \\
\text { opinião de gestores } \\
\text { escolhidos } \\
\text { intencionalmente. }\end{array}$ \\
\hline BVS & $\begin{array}{l}\text { Perspectivas e } \\
\text { Desafios da } \\
\text { Gestão Pública } \\
\text { no SUS }\end{array}$ & $\begin{array}{l}\text { Mendes } \\
\text { JDS, Bittar } \\
\text { OJNV }\end{array}$ & $\begin{array}{l}\text { Rev. Fac. } \\
\text { Ciênc. } \\
\text { Méd., v. 16, } \\
\text { n. 1, p. } 35 \text { - } \\
\text { 39, } 2014\end{array}$ & $\begin{array}{l}\text { Levantamento dos } \\
\text { principais problemas } \\
\text { enfrentados na Gestão } \\
\text { do SUS. }\end{array}$ \\
\hline BVS & $\begin{array}{l}\text { O papel do } \\
\text { Psicólogo na } \\
\text { Gestão dos } \\
\text { Recursos } \\
\text { Humanos }\end{array}$ & $\begin{array}{l}\text { Bárbara } \\
\text { Camila da } \\
\text { Silva }\end{array}$ & & $\begin{array}{l}\text { Identificação do atual } \\
\text { papel do psicólogo } \\
\text { organizacional na } \\
\text { Gestão de Recursos } \\
\text { Humanos em um } \\
\text { município do extremo } \\
\text { oeste de Santa } \\
\text { Catarina; }\end{array}$ \\
\hline Scielo & $\begin{array}{l}\text { Psicólogo } \\
\text { organizacional: } \\
\text { aplicador de } \\
\text { técnicas e } \\
\text { procedimentos } \\
\text { ou agente de } \\
\text { mudanças e de } \\
\text { intervenção nos } \\
\text { processos }\end{array}$ & $\begin{array}{l}\text { Azevedo } \\
\text { BM, Bolomé } \\
\text { SP }\end{array}$ & $\begin{array}{l}\text { Rev. } \\
\text { Psicol., } \\
\text { Organ. } \\
\text { Trab. v.1 } \\
\text { n.1, jun. } \\
2001\end{array}$ & $\begin{array}{l}\text { Identificação e análise } \\
\text { das necessidades } \\
\text { derivadas das } \\
\text { atividades de trabalho } \\
\text { do psicólogo } \\
\text { organizacional } \\
\text { brasileiro e suas inter- } \\
\text { relações com a } \\
\text { formação }\end{array}$ \\
\hline
\end{tabular}


Id on Line Revista Multidisciplinar e de Psicologia

Id on Line Multidisciplinary Journal and Psycology

\begin{tabular}{|c|c|c|c|c|}
\hline & $\begin{array}{c}\text { decisórios } \\
\text { organizacionais } \\
?\end{array}$ & & & profissional. \\
\hline Scielo & $\begin{array}{l}\text { O que pode } \\
\text { fazer o } \\
\text { psicólogo } \\
\text { Organizacional }\end{array}$ & $\begin{array}{l}\text { Bastos } \\
\text { AVB, } \\
\text { Martins } \\
\text { AHCG }\end{array}$ & $\begin{array}{c}\text { Rev. } \\
\text { Psicologia } \\
\text { ciência e } \\
\text { profissão, } \\
\text { vol } 10, \text { n. } 1, \\
2005\end{array}$ & $\begin{array}{l}\text { Desdobramento e } \\
\text { ampliação da análise } \\
\text { ocupacional do } \\
\text { psicólogo } \\
\text { organizacional. }\end{array}$ \\
\hline Scielo & $\begin{array}{l}\text { O hospital e a } \\
\text { formação em } \\
\text { saúde: desafios } \\
\text { atuais }\end{array}$ & $\begin{array}{l}\text { Feuerwerker } \\
\text { LCM; } \\
\text { Cecílio LCO }\end{array}$ & $\begin{array}{l}\text { Ciênc. } \\
\text { saúde col. } \\
\text { vol.12 n.4, } \\
\text { Jul /Ag } \\
2007\end{array}$ & $\begin{array}{l}\text { Contextualiza os } \\
\text { dilemas e tensões da } \\
\text { complexidade da } \\
\text { organização } \\
\text { hospitalar. }\end{array}$ \\
\hline BVS & $\begin{array}{l}\text { Contribuições } \\
\text { da psicologia } \\
\text { social para o } \\
\text { psicólogo na } \\
\text { saúde coletiva }\end{array}$ & Zurba MC. & $\begin{array}{l}\text { Psicologia } \\
\& \\
\text { Sociedade; } \\
\text { 23(n. spe.), } \\
5-11,2011 .\end{array}$ & $\begin{array}{l}\text { Apresenta } \\
\text { contribuições da } \\
\text { psicologia à saúde } \\
\text { coletiva. }\end{array}$ \\
\hline Scielo & $\begin{array}{l}\text { Fadiga no } \\
\text { trabalho: como } \\
\text { o psicólogo } \\
\text { pode atuar? }\end{array}$ & $\begin{array}{l}\text { Oliveira.JRS } \\
\text {,Viganó } \\
\text { MG, } \\
\text { Lunardelli } \\
\text { MCF,Canêo } \\
\text { FC. }\end{array}$ & $\begin{array}{l}\text { Psicol. } \\
\text { estud. } \\
\text { vol.15 no.3 } \\
\text { Maringá } \\
\text { Sept. } 2010\end{array}$ & $\begin{array}{l}\text { Buscou caracterizar a } \\
\text { síndrome da fadiga } \\
\text { crônica e o papel do } \\
\text { psicólogo nas } \\
\text { organizações. }\end{array}$ \\
\hline
\end{tabular}

\section{Resultados}

A partir daquilo que foi encontrado, estabeleceu-se o diálogo inicial da Psicologia Organizacional com as questões da Gestão do sistema de saúde brasileiro. Assim, para melhor 
Id on Line Revista Multidisciplinar e de Psicologia

Id on Line Multidisciplinary Journal and Psycology

compreensão do que está sendo discutido, os resultados foram agrupados e divididos em três seções, a saber: 1) Gestão da Saúde: Desafios atuais, 2) O psicólogo nas Organizações e 3) Contribuições da psicologia organizacional e do trabalho (POT) para a Gestão da Saúde. A seguir, cada uma destas temáticas será aprofundada.

\section{Gestão da Saúde: Desafios Atuais}

A Constituição brasileira, no ano de 1988, reconheceu a saúde como um direito de todo o cidadão e um dever do Estado, e determinou a base para a criação do SUS (Sistema Único de Saúde), que se alicerça nos princípios da universalidade, integralidade e participação social. Com o passar dos anos houve significativo avanço na implementação do SUS. Inovações institucionais foram realizadas, como um intenso processo de descentralização, que concedeu maior responsabilidade aos municípios na gestão dos serviços de saúde, além de viabilizar os meios para promover e formalizar a participação social na criação de políticas de saúde e no controle da execução do referido sistema (PAIM et al., 2011).

No entanto, após quase 30 anos de instituição do SUS no Brasil, inúmeros desafios ainda são enfrentados. Apesar de ser possível reconhecer nítidos avanços na ampliação do acesso da população às ações de saúde, tanto na atenção básica como naquelas de maior complexidade, a insastifação por parte dos seus usuários é visível, expressa nas manifestações populares que apontaram críticas a precariedade da saúde, dentre outras coisas. É necessário superar a dicotomia entre o subfinanciamento do sistema e suas "falhas" de gestão. Sem elencar um conjunto suficiente de problemas, detalhar melhor os cenários e as possibilidades concretas para aperfeiçoá-lo, provavelmente não se conseguirá o esperado progresso (MENDES e BITTAR, 2014).

Cabe salientar que o SUS também não dispõe de recursos humanos qualificados para a gestão do sistema. Os gestores do SUS são, em sua grande maioria, indicados por motivos políticos. No entanto, a saúde é uma área que requer conhecimento técnico amplo em todas as etapas: planejamento, execução e avaliação dos resultados, não podendo, portanto, ser neglicenciada em nenhuma de suas etapas de atuação (MENDES e BITTAR, 2014).

Ainda sobre esse assunto, Feuerwerker e Cecílio, pg 6. ( 2007) destacam que: 
O debate mundial acerca das melhores maneiras de organizar a atenção à saúde tem sido alimentado, por um lado, pela crescente compreensão sobre a medicalização e o papel constitutivo das práticas de saúde na conformação da ordem econômica e social do capitalismo no mundo ocidental e, de outro lado, pelos desafios impostos pela transição epidemiológica e o envelhecimento das populações, que ameaçam o financiamento dos sistemas de saúde em função de ineficácia, ineficiência, iniquidades decorrentes da incorporação de tecnologia sem critérios de custo benefício e da explosão de custos e gastos decorrentes do modelo hegemônico de pensar saúde.

Observando estas ideias, pode-se concluir que, sem recursos humanos com o devido preparo técnico e capacidade de planejar e fiscalizar a execução das ações pretendidas, se torna ilusório almejar a eficiência necessária.

As fragilidades de gestão e subfinanciamento têm emergido também como problemas relevantes em análises de estudiosos e gestores. Estes dão destaque no subfinanciamento para a redução da participação do setor público nos gastos em saúde no Brasil. Além das críticas à gestão serem amplas e variadas, mostram a dimensão dos problemas a serem solucionados. Quando se fala na rede hospitalar brasileira, pontua-se a fragilidade gerencial em diversos estabelecimentos de saúde e que estão longe de atender ao exigido para oferecer "uma assistência resolutiva, adequada e otimizada' (LORENZETTI et al, 2014).

Existe ainda um consenso entre os gestores da saúde de que a gestão nesse setor está entre os seus principais problemas, o que torna sua transformação um desafio prioritário. Destacam ainda como principais fragilidades o despreparo dos profissionais para o exercício da administração, lentidão na incorporação de novas tecnologias de informação e processos de gestão e de organização do trabalho. Fragilidades estas que estão diretamente interligadas, pois dependem umas das outras (LORENZETTI et al, 2014).

\section{O Psicólogo nas Organizações}

O profissional de saúde é, antes de tudo, um ser humano como qualquer outro. Por assim ser, quando em contato com seus semelhantes, por muitas vezes se coloca diante de sua própria vida, de seus conflitos e de sua história pessoal. Não são poucos os profissionais que atuam na saúde que, no desempenho de suas atividades do dia a dia, se deparam com situações de dor, angústia e sofrimento, por lidar com a morte, com pacientes em estágio 
Id on Line Revista Multidisciplinar e de Psicologia

Id on Line Multidisciplinary Journal and Psycology

terminal, familiares que acompanham seus entes queridos e cobram da equipe uma solução imediata. Se ele não tiver contato com esses fenômenos, correrá o sério risco de desenvolver mecanismos rígidos de defesa que podem prejudicá-lo tanto no âmbito profissional quanto no pessoal. Por outro lado, este profissional, ao entrar em contato com suas dores, pode utilizar o distanciamento como mecanismo de defesa. Sendo assim, cuidar de quem cuida é condição suficiente para desenvolver projetos de ações em prol da humanização da assistência (BASTOS; MARTINS, 1990).

Dentro de uma organização, o psicólogo deve promover ações preventivas, podendo analisar as situações de trabalho em relação ao modo como esta se organiza, ao ambiente físico, aos relacionamentos entre chefias e subordinados, entre outras, e propor, por meio de um diagnóstico organizacional, mudanças que sejam benéficas à saúde do trabalhador. Também é dever deste profissional buscar conhecimento sobre doenças relacionadas ao trabalho e seus sintomas (como a fadiga), a fim de permitir a identificação de trabalhadores que estejam sofrendo de transtornos mentais provenientes de sua condição de trabalho, bem como efetuar/propor as devidas mudanças no ambiente laboral. (OLIVEIRA, 2010).

O fazer da Psicologia no âmbito da saúde coletiva, no contexto da equipe interdisciplinar, requer que o profissional desenvolva algumas habilidades, tais como: capacidade de trabalhar em equipe, ética, utilizar linguagem acessível aos colegas de trabalho e população em geral, além de empatia. Vale dizer que, ao psicólogo, cabe também a tarefa de compreender como realiza seu exercício de poder durante o fazer psicológico, identificando qual o lugar que ocupa na complexa rede de forças que se confrontam no ambiente da saúde coletiva. Afinal, o psicólogo não é neutro, nem sua técnica. (ZURBA, 2011).

No entanto, o que se observa ainda é que a maior parte dos psicólogos esquiva-se da conquista de seu espaço nas organizações, e isso acaba por dar abertura para a inserção de profissionais de outras áreas do conhecimento. Isso decorre do fato de a atuação do psicólogo organizacional ainda estar centrada em funções como recrutamento, seleção e aplicação de testes psicológicos, evidenciando que o ele ainda não possui clareza sobre seu atual papel nas organizações. Limitando-se as suas atribuições tradicionais, o psicólogo acaba por isolar-se em funções previamente definidas e, consequentemente, deixa de ampliar suas possibilidades de contribuições para a organização a qual está vinculado, como na Gestão de serviços de saúde e não só de pessoas (BÁRBARA, 2014). 
Id on Line Revista Multidisciplinar e de Psicologia

Id on Line Multidisciplinary Journal and Psycology

\section{Contribuições da POT para a Gestão da Saúde}

A Psicologia é uma área de conhecimento que têm muitas vertentes de atuação, que por muitas vezes se confundem, tanto por parte dos usuários dos serviços quanto por parte de alguns profissionais. No início das atividades da Psicologia Organizacional, hoje chamada Psicologia Organizacional e do Trabalho, a atenção encontrava-se no recrutamento, seleção e avaliação. Os aspectos relacionados ao interesse, motivações e satisfação dos empregados aos poucos foram ampliados, de acordo com os interesses da organização, para então se estender à preocupação de compor equipes e aparatos organizacionais que resultassem no avanço da saúde, segurança e conforto, aliados à produtividade. Por meio disso, a atuação do psicólogo organizacional direcionou-se às práticas de saúde mental no trabalho, formação e desenvolvimento de pessoas, estresse, modos de inserção de pessoas com deficiência no seu local de trabalho, dentre tantas outras novas atribuições (CAMPOS et al, 2011 apud BÁRBARA, 2014 ).

Diante das constantes e velozes mudanças que as organizações e as sociedades sofreram com o passar dos anos, têm-se exigido dos psicólogos organizacionais uma disposição estratégica, com capacidade de gerenciamento de pessoas, facilitadores de mudanças, bem como de promotores de melhor qualidade de vida. A demanda que se apresenta na transição do século XX para o XXI está muito mais relacionada com atividades emergentes e com necessidades sociais do que com atividades tradicionais. O psicólogo organizacional não pode mais continuar sendo um mero aplicador de técnicas, que possibilitam apenas lidar com o humano como um ser isolado, dotado de deficiências e potencialidades. Ele precisa compreender o homem como um ser social, em constante interação com o meio, que se constitui nas relações que estabelece e nas atividades que executa (AZEVEDO; BOLOMÉ, 2001).

Em um panorama geral da Psicologia Organizacional, podemos perceber a necessidade do psicólogo na compreensão das causas e efeitos do desempenho humano no trabalho, auxiliando assim na predominância do foco individual e da Psicometria, para posteriormente centrar-se a nível grupal considerando os aspectos organizacionais no processo de adequação do homem ao trabalho. Só então o psicólogo incide sobre processos sociocomportamentais, sem deixar de considerar a organização como um todo nessa atuação. 
Esse desempenho tradicional do psicólogo que se debruça apenas sobre atividades técnicas, como atuação em recrutamento e seleção, por exemplo, apresenta-se hoje como ultrapassada, pelo fato de não atender mais as necessidades das organizações atuais. Este profissional deve ir a busca de outros instrumentos e atividades que lhe consolidem dentro da organização (BÁRBARA, 2014).

Atualmente, a Psicologia dispõe de conhecimentos para a atuação em equipes multidisciplinares, desenvolvendo ações coletivas com usuários, familiares, redes sociais e comunidades. Assim, esta ciência atua com foco na atenção, promoção da saúde e prevenção de doenças, especialmente nas ações que visam melhoria da qualidade de vida (CILIBERTI; SAADALLAH; BARROS, 2013).

A atuação da Psicologia em uma organização se dá por meio da aplicação dos conhecimentos e das técnicas psicológicas aos cuidados individuais e coletivos com a saúde e ao enfrentamento das doenças. Seu objeto é o sujeito psicológico e as suas relações com os fatores multideterminantes da saúde, tanto na Atenção Básica como na Atenção Especializada. Inclui, ainda, os diferentes grupos sociais e os seus problemas associados à promoção da saúde e prevenção de doenças, deixando claro que saúde não se limita a ausência de doença, o seu conceito é bem mais amplo. Segundo a Organização Mundial de Saúde (OMS) ela é "um estado de completo bem-estar físico, mental e social e não somente ausência de afecções e enfermidades" (CILIBERTI; SAADALLAH; BARROS, 2013).

O fato é que se o psicólogo restringe-se em sua própria atuação, não se inclinando na busca por aplicabilidade do seu saber e possibilidades de enriquecimento no seu fazer, ambicionando outras atividades e áreas de trabalho, perderá seu espaço nas organizações, obtendo como resultado um poder restrito e limitado (BÁRBARA, 2014).

\section{Considerações Finais}

Embora a realização desta revisão bibliográfica não tenha mostrado nenhuma referência direta do papel do psicólogo enquanto Gestor na saúde, o aporte teórico, aqui analisado e discutido, oferece uma gama diversa de contribuições, que podem e devem contemplar a temática em questão. 
A Psicologia Organizacional e do Trabalho (POT), na medida em que lança olhar sobre as questões pertinentes aos recursos humanos da Organização, desde o seu potencial para o trabalho, as motivações para o seu desempenho, bem como resolução dos conflitos em grupo, revela-se como um espaço aberto em potencial para contribuir de maneira satisfatória na administração das instituições de saúde.

Os cursos de Psicologia, assim como as formações específicas em POT, precisam ampliar as possibilidades de atuação desse profissional em sua grade curricular, trazendo o empoderamento das potencialidades desse saber. $\mathrm{O}$ acervo teórico aqui ilustrado pode e deve ser melhor explorado e utilizado para não só expandir os horizontes do Psicólogo, como também atrair o olhar dos Gestores de outras áreas para tantas possibilidades, beneficiando as demandas desse campo.

Uma das limitações do estudo foi à insuficiência de material recente produzido acerca do tema abordado. No que se refere à atuação do psicólogo na Gestão da Saúde, nada foi encontrado e, sobre a POT e os desafios da saúde no Brasil, pouquíssimo material num período mais recente.

Por fim, com este estudo, espera-se contribuir com a valorização da Psicologia e seu aprimoramento, além de ampliar as possibilidades de resolução às dificuldades enfrentadas pela saúde em nosso país, em parte pelo despreparo dos profissionais que a administram. É necessário ter a ciência psicológica como aliada à Gestão dos serviços em saúde, permitindo que profissionais e usuários sejam beneficiados pela sua atuação de forma correta e eficaz.

\section{Referências}

AZEVEDO, Beatriz Marcondes de; BOLOME, Sílvio Paulo. Psicólogo organizacional: aplicador de técnicas e procedimentos ou agente de mudanças e de intervenção nos processos decisórios organizacionais?. Rev. Psicol., Organ. Trab., Florianópolis , v. 1, n. 1, p. 181-186, jun. 20012 Disponível em <http://pepsic.bvsalud.org/scielo.php?script=sci_arttext\&pid=S1984$66572001000100008 \& \operatorname{lng}=$ pt\&nrm=iso $>$. acesso em 26 mar. 2016.

SILVA, Bárbara Camila da. O papel do Psicólogo na Gestão dos Recursos Humanos. Disponível em http://www.uniedu.sed.sc.gov.br/wp-content/uploads/2016/03/ARTIGOB\%C3\%81RBARA-CAMILA-DA-SILVA.pdf. Acesso em 16 de abril de 2016. 
BASTOS, Antônio Virgilio Bittencourt e GALVãO-MARTINS, Ana Helena Caldeira. O que pode fazer o psicólogo organizacional. Psicol. cienc. prof., 1990, vol.10, no.1, p.10-18. ISSN 1414-9893. Disponivel em http://www.scielo.br/pdf/pcp/v10n1/05.pdf. Acesso em 16 de abril de 2016.

BUENO, EDISON; AUGUSTINHO, MANOEL LOYOLLA; CARVALHO, THPF. Humanização-Construindo um novo conceito de fazer saúde. Campinas: Unicamp, 2003. Disponível em http://www.fef.unicamp.br/fef/sites/uploads/deafa/qvaf/tecnologia_cap3.pdf. Acesso em 26 de março de 2016.

CAMPOS, Keli Cristina de Lara et al. Psicologia organizacional e do trabalho - retrato da produção científica na última década. Psicol. cienc. prof., 2011, vol.31, no.4, p.702-717. Disponível em $\quad$ http://www.scielo.br/scielo.php?script=sci_arttext\&pid=S141498932011000400004. Acesso em 05 de março de 2016.

CECÍLIO, Luiz Carlos de Oliveira, et al. "A integralidade do cuidado como eixo da gestão hospitalar." Construção da integralidade: cotidiano, saberes e práticas em saúde 1 (2003): 197-210. Disponível em http://www.uff.br/saudecoletiva/professores/merhy/capitulos-07.pdf. Acesso em 05 de março de 2016.

CHAVES, Natália Azenha; O PAPEL DO PSICÓlOGO NA GESTÃO DE RECURSOS HUMANOS DAS ORGANIZAÇÕES. Rev. Cient. Elet. de Psic. Ano VIII n. 14, Mai 2010. Disponivel em http://faef.revista.inf.br/imagens_arquivos/arquivos_destaque/JiuYdHuqCYNfFAf_2013-513-15-8-36.pdf. Acesso em 22 de maio de 2016.

FEUERWERKER, LCM; CECÍLIO, LCO. O hospital e a formação em saúde: desafios atuais. Ciênc. saúde col. vol.12 n.4, Jul /Ag 2007. Disponivel em http://www.scielo.br/scielo.php?script=sci_arttext\&pid=S1413-81232007000400018. Acesso em 04 de junho de 2016.

LORENZETTI J, LANZONI GMM, ASSUITI LFC, PIRES DEP, RAMOS FRS. Gestão em Saúde no Brasil: Diálogo com gestores públicos e privados. Texto contexto Enferm., Abr-Jun de 2014. Disponivel em http://www.scielo.br/pdf/tce/v23n2/pt_0104-0707-tce-23-0200417.pdf. Acesso em 25 de março de 2016.

MENDES JDS, BITTAR OJNV, Perspectivas e Desafios da Gestão Pública no SUS. Rev. Fac. Ciênc. Méd., v. 16, n. 1, p. 35 - 39, 2014. Disponivel em http://revistas.pucsp.br/index.php/RFCMS/article/view/18597. Acesso em 22 de maio de 2016.

OLIVEIRA, Juliana Roman dos Santos et al. Fadiga no trabalho: como o psicólogo pode atuar?. Psicologia em Estudo. Departamento de Psicologia - Universidade Estadual de Maringá (UEM), v. 15, n. 3, p. 633-638, 2010. Disponível em: <http://hdl.handle.net/11449/8637>. Acesso em 14 de julho de 2016. 
PAIM J, Travassos C, Almeida C, Bahia L, Macinko J. O Sistema de Saúde Brasileiro: história, avanços e desafios. Séries Saúde no Brasil, maio de 2011. Disponível em http://actbr.org.br/uploads/conteudo/925 brazil1.pdf. Acesso em 28 de maio de 2016.

RUTHES, Rosa Maria; CUNHA, I. C. K. O. Os desafios da administração hospitalar na atualidade. Revista de Administração em Saúde, v. 9, n. 35, 2007. Disponível em http://www.ebah.com.br/content/ABAAABdYUAB/administracao-hospitalar. Acesso em 07 de maio de 2016.

ZANELLI, José Carlos. Formação e atuação em Psicologia Organizacional. Psicologia: ciência e profissão, v. 6, n. 1, p. 31-32, 1986. Disponível em http://www.scielo.br/scielo.php?script=sci_arttext\&pid=S1414-98931986000100010. Acesso em 22 de abril de 2016.

ZURBA, Magda do Canto. Contribuições da psicologia social para o psicólogo na saúde coletiva. Psicologia \& Sociedade; 23(n. spe.), 5-11, 2011. Disponível em http://www.ufrgs.br/seerpsicsoc/ojs2/index.php/seerpsicsoc/article/viewFile/3350/2005.

Acesso em 15 de julho de 2016.

\section{Como citar este artigo (Formato ABNT):}

MOREIRA, G.L.C.B. e SILVA, S.P.C. Desafios da Gestão na Saúde: Possíveis Contribuições da Psicologia Organizacional e do Trabalho. Id on Line Revista Multidisciplinar e de Psicologia, Outubro de 2016, vol.10, n.31, p. 3-15. ISSN 1981-1179.

Recebido: 16/07/2016.

Aceito: 19/07/2016 